\title{
Soft Soil Remediation with Permeable Low-Density Cellular Concrete (PLDCC)
}

\author{
Nico Sutmoller, ${ }^{1, *}$, Milton Gomez ${ }^{2}$, and John Kevern ${ }^{3}$ \\ ${ }^{1}$ Aerix Industries, 5902 McIntyre Street, Golden, CO 80403 \\ ${ }^{2}$ Aerix Industries, 7020 Snowdrift, Allentown, PA 18106 \\ ${ }^{3}$ University of Missouri - Kansas City (UMKC) 352 Flarsheim Hall, 5110 Rockhill Rd., Kansas City, MO 64110
}

\begin{abstract}
This paper addresses the feasibility of using permeable low-density cellular concrete (PLDCC) in soft soil remediation applications. In discussing this feasibility, the paper will review and evaluate data from recent studies conducted at the University of Missouri - Kansas City related to the physical properties of PLDCC, including permeability, infiltration, and void structure. This paper will cover the most typical applications for the utilization of PLDCC and take a brief look at the constructability and cost considerations. Three specific case studies are examined, including a wall abutment project in Bellingham, WA, a structural foundation project in New Orleans, LA, and a sinkhole remediation project in Chester County, PA. All three of these case studies utilized 25 to $35 \mathrm{pcf}$ (pounds per cubic foot) $\left(400 \mathrm{~kg} / \mathrm{m}^{3}\right.$ to 560 $\mathrm{kg} / \mathrm{m}^{3}$ ) PLDCC for soft soil remediation.
\end{abstract}

\section{Introduction}

Soft soil remediation is required for many geotechnical engineering and construction projects. A wide variety of traditional backfill materials have been utilized over the years to remediate soft soil in geotechnical applications. Remediation techniques range from removal and replacement of poor materials to chemical stabilization or mechanical strengthening. PLDCC is a material that is relatively new to the industry, combines ease of placement with consistent and uniform properties, and has proven to perform strongly in these applications. Because of its unique physical characteristics, PLDCC can provide a viable and cost-efficient alternative to traditional backfill materials, especially when used in wall abutments, structural foundations, and sinkhole and pavement remediation applications. This paper explores the chemical and physical properties of PLDCC and examines case studies in which PLDCC has been used effectively in each of these geotechnical applications.

\section{History of permeable low-density cellular concrete}

While non-permeable low-density cellular concrete (LDCC) has been around since the 1940s, permeable low-density cellular concrete (PLDCC) is a relatively new innovation, coming to the forefront in the early 2000s. The unique characteristic of PLDCC, in comparison to its non-permeable counterpart, is that the bubbles used to produce the lightweight structure also link and allow retention and transmission of water at or above that of the native soil. It is because of its unique, permeable nature that PLDCC provides a compressive strength, stability, and flexibility unmatched by traditional fill materials.

\section{Characteristics of permeable low- density cellular concrete}

According to the ACI 523 Guide for Cast-in-Place LowDensity Cellular Concrete [1], LDCC is defined as "concrete made with hydraulic cement, water, and preformed foam to form a hardened material having an oven-dry density of $50 \mathrm{lb} / \mathrm{ft}^{3}\left(800 \mathrm{~kg} / \mathrm{m}^{3}\right)$ or less" [1].

There are two types of foam used in making LDCC: preformed and agitated. The preformed foam is created by the dilution of a liquid foam concentrate with water in a predetermined ratio. This mixture is then processed through a foam generator to create a "shaving cream" consistency and combined with cementitious materials to create a cellular concrete. Agitated foam, in contrast, is produced by the processing of an engineered liquid concentrate into a concrete mixture, creating a controlled low-strength mixture (CLSM), also known as flowable fill.

While both preformed and agitated foam types conform to ACI industry standards, preformed foam conforms to ACI 523 [1], while agitated foam conforms to ACI 229 Report on Controlled Low-Strength Materials [2]. Because of its lower density, preformed cellular concrete provides more flexibility in applications than CLSM. CLSM generally has a density of 50 pcf or greater, while LDCC, by definition, features an oven dry density of less than $50 \mathrm{pcf}$. Therefore, according to ACI 229 [2], while cellular concrete is considered a flowable fill material, CLSM by definition cannot be considered a cellular concrete material [2].

\footnotetext{
* Corresponding author: nsutmoller@aerixindustries.com
} 


\subsection{Compressive strength and density}

Due to its method of production using a foam generator, LDCC features a comparatively high compressive strength. LDCC contains air cells in the same volume as coarse aggregate in a traditional fill material. These air cells withstand the mixing and pumping inherent in the application process and even at a $30 \mathrm{pcf}\left(481 \mathrm{~kg} / \mathrm{m}^{3}\right)$ density, hardened LDCC achieves a compressive strength that exceeds traditionally compacted backfill.

It is important to remember that LDCC and PLDCC normally replace traditionally compacted backfill and are not designed to be the wearing surface of a project. Ideally, compacted backfill has a compressive strength of 50 to $80 \mathrm{psi}(0.34$ to $0.55 \mathrm{MPa})$, which enables hand excavation. In comparison, a $30 \mathrm{pcf}\left(481 \mathrm{~kg} / \mathrm{m}^{3}\right) \mathrm{LDCC}$ will provide an average predictable and uniform $140 \mathrm{psi}$ $(0.97 \mathrm{MPa})$, exceeding traditionally compacted backfill, yet still excavatable [3].

Table 1 (ACI Committee 523) provides ranges of strength and density for typical cellular concrete materials. Of the mixtures shown, each contains a volume comprised of $70 \%$ to $75 \%$ foam (30 pcf [ 481 $\left.\mathrm{kg} / \mathrm{m}^{3}\right]$ ), with compressive strength equal to or exceeding that of compacted soil. It is this mixture of high compressive strength and lightweight characteristics that make low-density cellular concrete an effective solution for soil remediation applications. Figure 1 [4] illustrates the positive correlation between compressive strength and the cast (wet) density of PLDCC.

Table 1. Cellular concrete material strength and density.

\begin{tabular}{|c|c|c|c|c|c|}
\hline \multicolumn{2}{|c|}{$\begin{array}{c}\text { Oven-Dry } \\
\text { Density }\end{array}$} & $\begin{array}{c}\text { Usual Range of } \\
\text { Compressive } \\
\text { Strength at } 28 \\
\text { Days }\end{array}$ & \multicolumn{2}{c|}{$\begin{array}{c}\text { Modulus of } \\
\text { Elasticity }\end{array}$} \\
\hline $\mathbf{l b} / \mathbf{f t}^{3}$ & $\mathbf{k g} / \mathbf{m}^{3}$ & psi & MPa & $\mathbf{1 0}^{3}$ psi & GPa \\
\hline 20 to & 320 to & 70 to & 0.48 to & 30 to & 0.21 to \\
25 & 400 & 125 & 0.86 & 52 & 0.36 \\
\hline 25 to & 400 to & 125 to & 0.86 to & 52 to & 0.36 to \\
30 & 480 & 225 & 1.55 & 89 & 0.61 \\
\hline 30 to & 480 to & 225 to & 1.55 to & 89 to & 0.61 to \\
35 & 560 & 350 & 2.41 & 135 & 0.93 \\
\hline 35 to & 560 to & 350 to & 2.41 to & 135 to & 0.93 to \\
40 & 640 & 450 & 3.10 & 183 & 1.26 \\
\hline 40 to & 640 to & 450 to & 3.10 to & 183 to & 1.26 to \\
50 & 800 & 750 & 5.17 & 320 & 2.21 \\
\hline
\end{tabular}

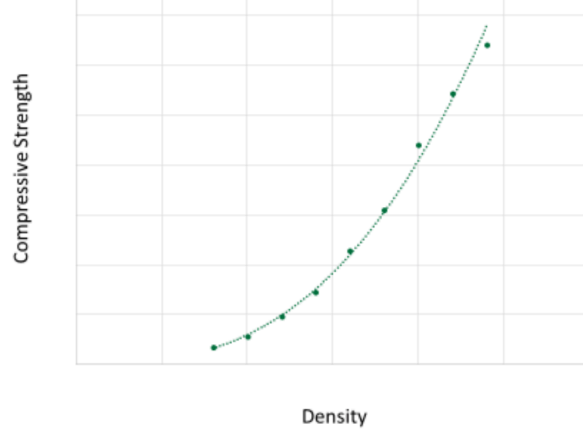

Fig. 1. correlation between compressive strength and the cast (wet) density of PLDCC

\subsection{Permeability}

The difference in the permeability characteristics of PLDCC versus LDCC relate to the chemical composition of the foam concentrate in the mixtures. While PLDCC contains a coalesced cellular structure, non-permeable LDCC contains the cellular structure in its original phase.

PLDCC is highly permeable when compared to soil and other traditional fill materials (Refer to Table 2 below for the rates of soil permeability, which range from $10^{-1}$ to $10^{-9} \mathrm{~cm} / \mathrm{sec}$ ). Table 2 also notes the permeability rates of traditional fill materials, such as sand and clay, which generally range from $10^{-3}$ to $10^{-7}$ $\mathrm{cm} / \mathrm{sec}$. In contrast, PLDCC has a minimum permeability rate of $10^{-3} \mathrm{~cm} / \mathrm{sec}$.

Table 2. Coefficient of permeability.

\begin{tabular}{|c|c|c|c|c|}
\hline \multicolumn{5}{|c|}{ Coefficient of Permeability $k(\mathrm{~cm} / \mathrm{sec})(\log$ scale) } \\
\hline & $10^{2} 10^{1}$ & $\begin{array}{lll}1.0 & 10^{-1} & 10^{-2}\end{array}$ & $\begin{array}{llll}10^{-3} & 10^{-4} & 10^{-5} & 10^{-6}\end{array}$ & $\begin{array}{lll}10^{-7} & 10^{-8} & 10^{-9}\end{array}$ \\
\hline 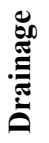 & \multicolumn{2}{|r|}{ Good } & Poor & $\begin{array}{l}\text { Practically } \\
\text { Impermeable }\end{array}$ \\
\hline 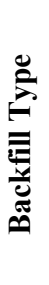 & $\begin{array}{l}\text { Clean } \\
\text { gravel }\end{array}$ & \begin{tabular}{|} 
Clean sands, \\
dean, sand \\
and gravel \\
mixture, \\
PLDCC
\end{tabular} & $\begin{array}{l}\text { Very fine, sand, } \\
\text { organic and } \\
\text { inorganic silts, } \\
\text { mixtures of sand } \\
\text { silt and clay, } \\
\text { glacial till, } \\
\text { stratified day, } \\
\text { LDCC }\end{array}$ & $\begin{array}{l}\text { "Impermeable" } \\
\text { soils, e.g., } \\
\text { homogeneous } \\
\text { clays below } \\
\text { zone of } \\
\text { weathering }\end{array}$ \\
\hline
\end{tabular}

One of the unique properties of PLDCC is that its permeability does not negatively affect its compressive strength. With some permeable materials, permeability can reduce compressive strength as the material becomes more saturated. That is not the case with PLDCC, which maintains its compressive strength over time and through various levels of saturation, as is evident in Figure 2 below.

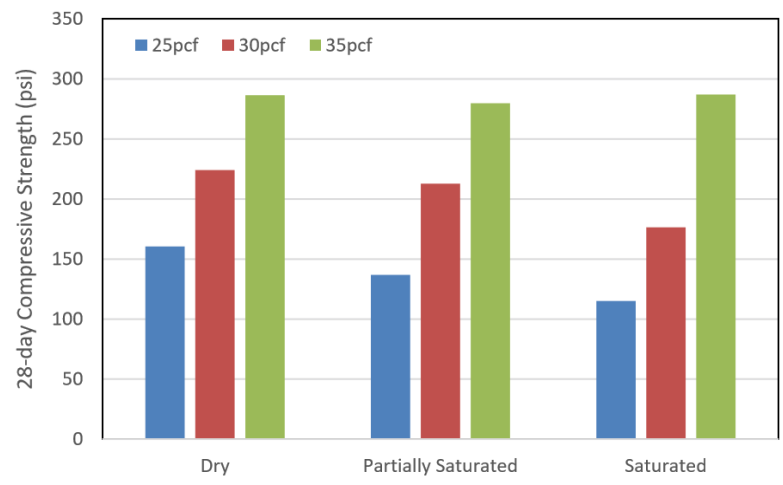

Fig. 2. PLDCC compressive strength.

The compressive strength of the PLDCC tested in this ASTM 28-day compressive strength study [5] remains constant when the material is dry, partially saturated, and fully saturated. Testing in this study was 
completed per ASTM C495/C495M-12 Standard Test Method for Compressive Strength of Lightweight Insulating Concrete and in all cases exceed the minimum ASTM strength requirements.

The compressive strength and stability of PLDCC has been evidenced in several geotechnical engineering soil stabilization projects. This paper will highlight three projects, all of which utilized PLDCC in different applications with high-performance statistics.

The use of PLDCC as a soil stabilization material in an abutment wall was demonstrated in 2015 on State Route 542 in Bellingham, Washington. A portion of State Route 542 contained a wooden bridge spanning Anderson Creek that was constructed with two culverts, which over the years had become clogged with debris and required frequent maintenance. Washington State Department of Transportation determined the need to restore the creek to its natural state and eliminate the debris collection, which restricted fish passage.

One of the challenges was that the roadway was built directly on top of the soft soil embankment, which compounded the sedimentation and collection of debris. The new bridge structure had to be built in a way that remediated the soft soil settlement and effectively stabilized the bridge structure. PLDCC was used to build two 50-foot high wall abutments. The initial slurry was mixed at a 0.5 water-to-cement ratio and foam was added to produce a 25 pcf PLDCC material. Placement production was achieved with two-foot lifts, one at a time, with wire mesh installed directly after placement to create the form work. Each lift was allowed to set for one hour before the next lift was placed and the compressive strength was tested. The PLDCC yielded a compressive strength of more than 100 pounds per square inch (psi) in 28 days.

\subsection{Hydrostatic pressure reduction}

The permeable characteristics of PLDCC can contribute to significant reduction in below-grade hydrostatic pressure. Hydrostatic pressure decreases relative to the infiltration rate, which decreases relative to the permeability of the below-grade fill product. The permeability rate directly correlates to the infiltration rate of PLDCC, which reduces the potential for hydrostatic pressure. Figure 3 below [5] demonstrates this characteristic of PLDCC.

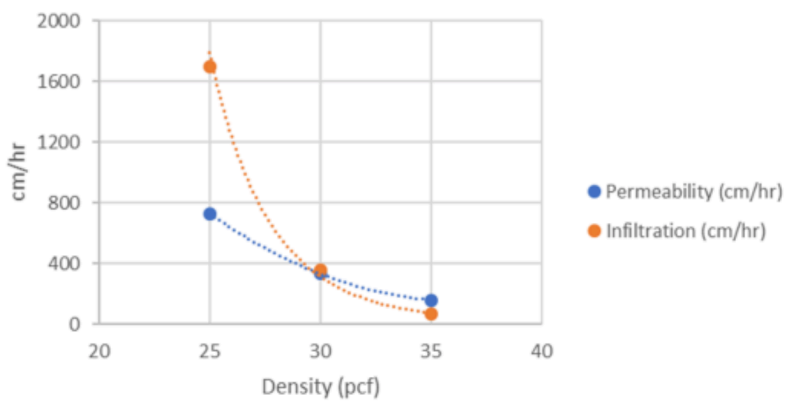

Fig. 3. PLDCC permeability/infiltration.
It is important to note that while the permeability and infiltration increase relative to each other, the density of the PLDCC material decreases in relation to these increases. As demonstrated in Table 3, under laboratory conditions, the void content along with the permeation and thermal resistivity of PLDCC decreases with increased unit weight. This relationship between decreased density and increased infiltration and permeability is consistent with other granular materials, including conventional permeable concrete. In order to counter any buoyancy concerns, it is recommended, under both in-field and design conditions, to consider a maximum infiltration rate of $50-55 \%$. Full saturation is unlikely, especially in field conditions.

Table 3. Basic Characterization of PLDCC.

\begin{tabular}{|c|c|c|c|}
\hline Density & $\begin{array}{c}25 \mathrm{pcf} \\
\left(400 \mathrm{~kg} / \mathrm{m}^{3}\right)\end{array}$ & $\begin{array}{c}30 \mathrm{pcf} \\
\left(480 \mathrm{~kg} / \mathrm{m}^{3}\right)\end{array}$ & $\begin{array}{c}35 \mathrm{pcf} \\
\left(560 \mathrm{~kg} / \mathrm{m}^{3}\right)\end{array}$ \\
\hline $\begin{array}{c}\text { Dry UW, pcf } \\
\left(\mathbf{k g} / \mathbf{m}^{3}\right)\end{array}$ & $13.4(215)$ & $16.5(265)$ & $18.9(305)$ \\
\hline Voids (\%) & 89.6 & 87.1 & 85.9 \\
\hline $\begin{array}{c}\text { Permeability, } \\
\text { in/s (cm/s) }\end{array}$ & $0.08(0.20)$ & $0.04(0.09)$ & $0.02(0.05)$ \\
\hline $\begin{array}{c}\mathbf{C 1 7 0 1} \\
\text { Infiltration, } \\
\text { in/s (cm/s) }\end{array}$ & $0.19(0.47)$ & $0.04(0.10)$ & $0.007(0.019)$ \\
\hline $\begin{array}{c}\text { Resistivity } \\
\left({ }^{\circ} \mathbf{C ~ c m} / \mathbf{W}\right)\end{array}$ & 1086 & 748 & 658 \\
\hline
\end{tabular}

The hydrostatic pressure reduction capabilities of PLDCC have been proven in its application as a sinkhole remediation fill material. Sinkholes are often caused by changes in hydrostatic pressure for example, when moisture is suddenly removed from soil. PLDCC, with a statistically high permeability and infiltration rate, reduces hydrostatic pressure and stabilizes soil, preventing the formation of sinkholes. These characteristics were illustrated in a recent project completed by the Pennsylvania Department of Transportation on Route 30 in Chester County.

In lieu of backfilling this excavation with relatively impermeable flowable fill, lean concrete, or soil, which are typical, 1,200 cubic yards of PLDCC with a wet cast unit weight of $35 \mathrm{pcf}$ was used to remediate this sinkhole. PLDCC is ideal for applications that require subgrade drainage because it mitigates any buoyancy uplift concerns. The PLDCC was pumped through a three-inch hose and installed using four-foot lifts at a depth of approximately three feet below the median subgrade. For this project, the water runoff needed to flow through the PLDCC directly to the rock fractures, without transporting soil in its flow. In contrast, if impervious fill material had been used, rainwater could have flowed along the perimeter of the excavation and potentially formed another sinkhole.

Another recent application that exhibited the hydrostatic pressure reduction capabilities of PLDCC occurred at the Louis Armstrong International Airport in New Orleans, Louisiana. This project included the construction of an airfield lighting vault, which housed all the high-voltage cables, current regulators, and 
control panels that facilitate the operation of the airfield lighting system.

One of the challenges with this construction was that the lighting vault was to be built on top of soil that consisted of black clay with an extremely high-water table. The fill material used around the vault's foundation needed to facilitate significant storm water drainage, stabilize the soft soil. To control silt infiltration into the PLDCC, a silt fabric was placed before the PLDCC (28 pcf) was installed in two lifts of two feet for a total depth of four feet and a total volume of 3,000 cubic yards.

\section{Summary and Conclusions}

Soft soil remediation is a significant challenge for the geotechnical engineering and construction industries. As evidenced by its unique physical characteristics high permeability, high infiltration, high compressive strength, and low density PLDCC can be used effectively in soft soil remediation. Its high performance in these types of applications has been evidenced by numerous case studies, including the three projects highlighted in this paper. PLDCC, specifically at 25 to 35 pcf, offers a viable solution for soft soil remediation with the added advantages of hydrostatic pressure reduction.

This paper relies on research completed and data gathered by a number of industry professionals who must be acknowledged. These individuals include Rich Palladino, President of Aerix Industries; Joe Feiler, Senior Technical Engineer at Aerix Industries; Brian Masloff, Senior Research Scientist at Aerix Industries; and Sami Safi, Operations and Technical Support Engineer at Aerix Industries.

\section{References}

1. ACI (American Concrete Institute) Committee 523. (2007). "Guide for Cast-in-Place Low-Density Cellular Concrete." ACI, Farmington Hills, MI.

2. ACI (American Concrete Institute) Committee 229. (2013). "229R-13 Report on Controlled LowStrength Materials." ACI, Farmington Hills, MI.

3. Aerix Industries. (2013). "Guidelines for Cellular Concrete Strength and Density." Aerix Industries, Golden, CO.

4. Aerix Industries. (2017). "Pervious Cellular Concrete (25-35 PCF)." STGEC, Savannah, GA, December 2017.

5. UMKC (University of Missouri, Kansas City). (2018). "Basic Characterization of Permeable Concrete." Report presented to Aerix Industries. 